RESEARCH ARTICLE

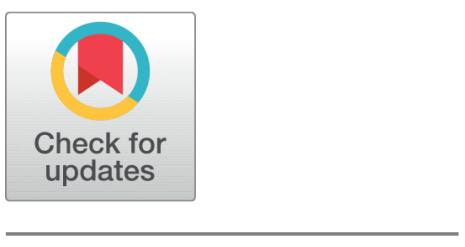

OPEn ACCESS

Received: 01.01.2021

Accepted: 28.04 .2021

Published: 18.09 .2021

Citation: Muangprakaew P, Luangsa-Ard N, Komasatitaya J (2021) Study of Physical, Mechanical, and Barrier Properties in Linear Low-Density Polyethylene Mixed with Silver Zeolite Nanoparticles (Ag-zeolite) Film. Indian Journal of Science and Technology 14(31): 2526-2534. https://doi.org/ 10.17485/IJST/v14i31.1

* Corresponding author.

Pradtana.por@mail.kmutt.ac.th

Funding: None

Competing Interests: None

Copyright: (c) 2021 Muangprakaew et al. This is an open access article distributed under the terms of the Creative Commons Attribution License, which permits unrestricted use, distribution, and reproduction in any medium, provided the original author and source are credited.

Published By Indian Society for Education and Environment (iSee)

ISSN

Print: 0974-6846

Electronic: 0974-5645

\section{Study of Physical, Mechanical, and Barrier Properties in Linear Low-Density Polyethylene Mixed with Silver Zeolite Nanoparticles (Ag-zeolite) Film}

\author{
Pradtana Muangprakaew ${ }^{1 *}$, Nucharin Luangsa-Ard ${ }^{2}$, Juntira Komasatitaya ${ }^{3}$ \\ 1 The Petchra Prajom Klao Scholar Master Student in Department of Printing and Packaging \\ Technology, Faculty of Industrial Education and Technology at King Mongkut's University of \\ Technology Thonburi (KMUTT), Bangkok, 10140, Thailand \\ 2 Associate Professor in Department of Printing and Packaging Technology, Faculty of \\ Industrial Education and Technology at King Mongkut's University of Technology Thonburi \\ (KMUTT), Bangkok, 10140, Thailand \\ 3 Assistant Professor in Department of Printing and Packaging Technology, Faculty of \\ Industrial Education and Technology at King Mongkut's University of Technology Thonburi \\ (KMUTT), Bangkok, 10140, Thailand
}

\section{Abstract}

Background/Objectives: The primary goal of using active packaging is to extend the shelf life of products inside the package. This research aimed to study the properties of LLDPE with Ag-zeolite nanoparticles to extend product shelf-life. Methods/Statistical analysis: In this research, LLDPE films combined with Ag-zeolite at 0.5 and $1 \%$ wt. were produced by using a twinscrew extruder and a blown film extruder. The inspected properties included the physical properties, the mechanical properties, and the barrier properties. The data were analyzed by performing the one-way ANOVA analysis and paired comparison analysis, using the IBM SPSS software with the confidential statistics of 95\%. Findings: The analyzed physical properties of the plastic films in this study showed that, when Ag-zeolite was added to the LLDPE, the yellowness index of the film increased. When Ag-zeolite was added to LLDPE plastic films, it did not appear to alter the tested plastics' melting temperature $(\mathrm{Tm})$, crystallization temperature (Tc), or the crystallinity of all the plastic films and conformed to the FT-TR and XRD curves. Ag-zeolite agent's dispersion on the film's gloss seemed to be aligned with the SEM images. However, although adding an Ag-zeolite agent into LLDPE film contributed to the change in color, it did not affect the polymer's characteristics and structure. Lastly, the mechanical properties across the LLDPE plastic films mixed with Ag-zeolite agent statistically significantly decreased, but the barrier properties of the films did not change. Applications: The study results could be an alternative for manufacturing active packaging. Novelty: Color changing of LLDPE film mixed with Ag-zeolite agent, but it did not change the polymer's characteristic or structure. 
Keywords: Antibacterial agent; Linear lowdensity polyethylene (LLDPE); Physical properties; Plastic film; Silver zeolite nanoparticles (Ag-zeolite); Yellowness index

\section{Introduction}

The properties of plastics are used to determine the quality of the packaging that will be manufactured ${ }^{(1)}$. This information underlies product design which will then become the actual production. Properties of plastics can be divided into three properties, including the physical properties (e.g., optical properties, polymer morphology, thermal properties, etc.), the mechanical properties (e.g., tensile strength and elongation at break, tear strength, burst strength, etc.), and the barrier properties (oxygen transmission rate (OTR) and water vapor transmission rate (WVTR) ${ }^{(2)}$.These properties are particularly important for packaging production and thus are also crucial for both designers and manufacturers. For example, the production of plastic bags requires the properties of plastic that is flexible and can be resistant to a certain amount of weight. In addition, food plastic wrap must be resistant and stretchable with decent permeability of water vapor and oxygen. If plastic material or properties are inappropriate, it may result in damaged packages. The general properties of plastic therefore must be verified according to the three functional properties before the process of food packaging manufacture.

Food packaging is particularly salient for ensuring and maintaining food quality and food safety before provided to consumers, given that it protects the food from bacterial contamination, which is associated with an individual's health risk. Amongst the available options, flexible packaging is widely used in the food packaging production process. It is also a common food contact material for manufacturing fresh food, chilled food, vegetables, and fruits. This is because plastic is highly efficient to produce, and it can be sealed with heat and vacuum. The examples of plastic used for manufacturing food packaging include polyethylene (PE), polypropylene (PP), polystyrene (PS), polyvinyl chloride (PVC), polyethylene terephthalate (PET), and acrylonitrile butadiene styrene (ABS) ${ }^{(3)}$.

Linear low-density polyethylene (LLDPE); $0.915-0.935 \mathrm{~g} / \mathrm{cm}^{3}$ density shares somewhat similar properties to LDPE, but it consists of a shorter branch, a better orderly arranged structure, and it is opaquer than $\operatorname{LDPE}^{(4)}$. Meanwhile, LLDPE film is more common in the manufacture of laminate layers. It is also popular for the production of food packaging in various applied technology. For example, Tornuk, F. et al. (2015) studied LLDPE-based food packaging incorporated with nano clays grafted. The study reported LLDPE mixed with nano clays grafted bags, in which the package fresh beef could inhibit Escherichia coli and extended the shelf life of meat products ${ }^{(5)}$. Furthermore, Panrong, T. et al. (2019) described thermoplastic starch and green tea mixed with LLDPE films for active packaging of meat and oil-based products. The results showed that LLDPE blended with thermoplastic starch, released from green tea, could inhibit bacterial growth ${ }^{(6)}$.

Active packaging can sense the internal and external environment responding by changing its properties or attributes. The primary goal of using active packaging is to extend the shelf life of products inside the package. Examples of active packaging include modified atmosphere (MA), controlled atmosphere (CA), and antimicrobial packaging, which is capable of disinfecting and restraining the growth of bacteria by adding up antibacterial agents such as organic acid groups (acetic acid, benzoic acid, and lactic acid), enzyme groups (lysozyme, glucose oxidase, and lactoperoxidase) and metal groups (silver, copper, and zirconium) ${ }^{(7)}$ during plastic manufacturing. The Agzeolite was one of the popular additives mixed with plastic. Ag-zeolite consists of silver ions $\left(\mathrm{Ag}^{+}\right)$, and zeolite; additionally, the operation of Ag-zeolite includes silver ions 
$\left(1 \times 10^{-9}\right)$, which is responsible for effusion and inhibition of the enzyme inside bacteria operation, which is associated with bacteria's growth. Silver ions are synthesized from silver nitrate $\left(\mathrm{AgNO}_{3}\right)$, then the zeolite $\left(1 \times 10^{-6}\right)$ or $\left(\mathrm{Al}_{2} \mathrm{SiO}_{5}\right)$, inorganically acting as a supporter of silver ions since the internal structure is porous ${ }^{(8)}$. Dutta, P. et al. (2019) described the operating mechanism of silver ions' bacteria inhibition and the operation of zeolite as a supporter of silver ions, and a catalyst and an absorber were discussed. The studies which involved the mix of Ag-zeolite with plastic include ${ }^{(9)}$, for instance, Le, A. et al. (2016), which examined polypropylene (PP) mixed with silver zeolite (AgNPs-Zeolite) at 0, 40, 80, and 160 ppm with twin rotating screw, followed by the test of the properties of packaging operation (tensile strength and elongation at break), and antibacterial efficiency test was also conducted ${ }^{(10)}$. Meanwhile, authors in Carbone, M. et al. (2016) who investigated the use of active packaging to preserve fresh foods (meats, fruits, and dairy products), containing two significant polymer preparations, including petroleum polymer (LDPE, PVC, EVOH, and PS) and biopolymer (cellulose, starch, agar, and pollutant), before testing the antibacterial efficiency ${ }^{(11)}$.

Given the salience of research into this area, this study aims to properties of LLDPE mixed with Ag-zeolite (at 0.5 and $1 \% \mathrm{wt}$ ). The properties which the researchers intend to inspect are physical properties (yellowness index, differential scanning calorimetry (DSC), scanning electron microscope (SEM), fourier-transform infrared spectroscopy (FT-IR), and xray diffraction (XRD)), mechanical properties (tensile strength, elongation at break, tear resistance, heat seal strength, and puncture resistance), and barrier properties (oxygen transmission rate (OTR) and water vapor transmission rate (WVTR)). The results were an alternative to considering for manufacturing of active packaging.

\section{Materials and Methods}

\subsection{Material and instrument used}

Linear low-density polyethylene resin; LLDPE (PTT Polymer Marketing Company Limited, Thailand), silver zeolite nanoparticles (Ag- zeolite) (Sinanen Zeomic Co., Ltd., Japan), twin-screw extruder from Colin brand in the model of T-20 (Lab Tech Engineering co. Ltd., Thailand), and blown film extruder from Betol brand in the model of 2525 (Lab Tech engineering co. Ltd., Thailand).

\subsection{The preparation of LLDPE film mixed with Ag-zeolite}

LLDPE resins were mixed with $\mathrm{Ag}$ - zeolite ( 0.5 and $1 \% \mathrm{wt}$ ) as a compounding pellet by the twin-screw extruder in the machine condition, $190-200{ }^{\circ} \mathrm{C}, 25-30 \mathrm{rpm}$. of velocity, $65 \mathrm{Nm}$ of torque, and 18-19 bar of pressure. Then, the blown film extruder was used to produce films in the machine condition, $195-200{ }^{\circ} \mathrm{C}, 40 \mathrm{rpm}$, velocity, $75 \mathrm{Nm}$ of torque, and 292 bars of pressure. Last, the manufactured plastic films contain an average thickness of films approximately 0.05-0.06 $\mathrm{mm}$.

\subsection{Material testing}

\subsubsection{Physical properties}

Yellowness index (YI; ASTM - D1003; Ci7600 benchtop spectrophotometer (x-rite), USA). X-ray fluorescence spectrometry (WDXRF; Bruker S8 Tiger, USA); 4kW, 60kV max, 171mA max. Differential scanning calorimetry (DSC; ASTM E967-18; Differential scanning calorimeter $204 \mathrm{~F} 1$, Phoenix, Thailand); 50-200 ${ }^{\circ} \mathrm{C}$ temperature, five ${ }^{\circ} \mathrm{C} / \mathrm{min}$ average heating. Scanning electron microscope images (SEM; ASTM F1372-93; Scanning electron microscope and energy dispersive X-ray spectrometer (SEM-EDS), IT-500 HR, Japan); 500 x, 15.0 kV, $50 \mu \mathrm{m}$ magnification. Fourier transform infrared spectrometer (FT-IR; Perkin Elmer, Spectrum One, USA) FTIR spectra were recorded through approximately 32 scans by the wavenumber range 4000$450 \mathrm{~cm}^{-1}$ with a wavenumber resolution of $4 \mathrm{~cm}^{-1}$ at room temperature ${ }^{(12)}$. X-ray diffraction (XRD; Bruker AXS Model D8 discover, USA) $2 \times 2 \mathrm{~cm}$ specimen size, Cu target, $40 \mathrm{kV}$ voltage, $40 \mathrm{~mA}$ current, the PXRD patterns were the major determinant of the crystalline structure of Ag-zeolite in wide-angle range of $2 \theta\left(5^{0}<2 \theta<80^{\circ}\right)$, wavelength $(\lambda)$ of $0.15481 \mathrm{~nm}$ at the scan speed of $4^{0} / \mathrm{min}^{-1}$ was used for these measurements and were recorded ${ }^{(13)}$. Gloss [ASTM-D2457-13; Gloss Meter, AG-106B, AG-1268B, Graigar, Thailand].

\subsubsection{Mechanical properties}

Tensile strength and elongation at break (ASTM D882-18; Universal testing machine, UK) $15 \times 100 \mathrm{~mm}$ Specimen size, 50 $\mathrm{mm} / \mathrm{min}$ speed, five $\mathrm{kg} / \mathrm{N}$ load cell. Tear resistance (ASTM D1938-14; Universal testing machine, UK) $30 \times 75 \mathrm{~mm}$ specimen size; $50 \mathrm{~mm}$ incision length, $50 \mathrm{~mm} / \mathrm{min}$ speed, five $\mathrm{kg} / \mathrm{N}$ load cell. Punch resistance (ASTM F306-16; Instron model 1123, USA). Heat seal (ASTM F88; I Universal testing machine, UK) $10 \times 75 \mathrm{~mm}$ specimen size, $130-155^{\circ} \mathrm{C}$ temperature used heat 
sealing.

\subsubsection{Barrier properties}

Oxygen transmission rate (OTR; ASTM D3985; Illinois 80001L, Thailand). Water vapor transmission rate (WVTR; ASTM E96; Mocon permatran-w $3 / 33$, USA) $38{ }^{\circ} \mathrm{C}$ temperature, $90 \%$ of relative humidity.

\subsection{Data processing and value analysis}

All the data gathered from the experiment were analyzed by one-way ANOVA analysis and paired comparison analysis with the IBM SPSS Statistics 21 program in the confidential statistics of $95 \%$.

\section{Results and Discussion}

\subsection{Physical properties}

The results indicated a statistically significant difference in the yellowness index (YI) of LLDPE/Ag-zeolite films at 0.5 and $1 \%$ wt; the manufactured films yielded an increase of YI. As shown in [Figure 1(a)], the CIE L ${ }^{*}{ }^{*} b^{*}$ graph of LLDPE mixed with Ag-zeolite at 0.5 and $1 \%$ wt demonstrated that an increase of Ag-zeolite agent in the plastic film had effects on the decreased lightness value $\left(L^{*}\right)$, while the yellow value $\left(b^{*}\right)$ increased. This was aligned with [Figure 1(b)], showing the existence of the visible light spectrum (360-750 nm) on the pure LLDPE and LLDPE/Ag-zeolite at 0.5 and $1 \%$ wt films. Additionally, by adding Ag-zeolite onto the film, it was discovered that there was a change in the wavelength at $360-500 \mathrm{~nm}$ (blue light, which is the complementary color of the yellow light). Following Pridmore et al's (2009) claim of the complementary colors, it is confirmed that blue light was absorbed while reflecting yellow light on an object ${ }^{(14,15)}$. Even more, in the study of Boschetto et al. (2012), which examined polyethylene composite film mixed with Ag-zeolite $\mathrm{Y}$ at $1-10 \%$ wt produced by the wet casting and pressing technique, the color results of LDPE films $\left(\mathrm{L}^{*} \mathrm{a}^{*} \mathrm{~b}^{*}\right)$ was found to be associated with the decrease of the lightness value $\left(\mathrm{L}^{*}\right)$ and the increased yellow value $\left(\mathrm{b}^{*}\right)^{(16)}$. Morones et al. (2005) also claimed that silver appeared to have a high probability of reacting with Phosphorus (P) and Sulphur (S) compounds ${ }^{(17)}$, and so it was possible that those compounds may be the primary reason for the increase of yellowness index in LLDPE mixed with Ag-zeolite. Therefore, the plastic resins were analyzed to identify the substances' elements through X-ray Fluorescence (XRF). It was discovered that the resins used in the existing experiment consisted of Phosphorus (P) and Sulphur (S). Instead, it appeared to be affected by the yellowness of the films, which was in line with what was displayed in [Figure 1(c)] since the silver ions reacted to the additives, Phosphorus (P) and Sulphur (S), in the plastic resins contributing to an appearance of yellowness on the plastic films ${ }^{(17)}$. This evidence supported the change of color of the films with LLDPE mixed with Ag-zeolite in this study. In the manufacturing process, for the utmost advantages of both the manufacturers and customers, avoiding the use of LLDPE resin, which consists of the additive agents mentioned earlier, is compulsory.

Differential scanning calorimetry (DSC) of pure LLDPE and LLDPE mixed Ag-zeolite plastic film resulted at 0.5, and 1\% wt did not show a statistically significant difference $(p>0.05)$ as shown in [Figure 2(a), (b)]. Also, the amount of agent added to the films did not have an impact on the melting temperature $(\mathrm{Tm})$, which was $121-121.65{ }^{\circ} \mathrm{C}$, the crystallization temperature (Tc) which ranged from 105.2 to $106.7^{\circ} \mathrm{C}$, and the crystallinity of plastic films \%Xc which was $22.3-22.71 \%$. In their study, Passador et al. (2012) reported the DSC value of pure LLDPE emerging from their experiment, indicating that the melting temperature (Tm) was $124{ }^{\circ} \mathrm{C}$, during the crystallization temperature (Tc) was $106^{\circ} \mathrm{C}$, which was consistent with the findings in this research ${ }^{(18)}$. Besides, Boschetto et al. (2012) revealed the DSC value of LLDPE mixed with Ag-zeolite Y at 1-10 \%wt, produced by the wet casting and pressing methods. The results showed that the inclusion of Ag-zeolite agent in LDPE film did not play any role in both the melting (Tm) and crystallization temperature (Tc). When Ag-zeolite was added to the film, it did not alter the polymeric material characteristics ${ }^{(16)}$.

Fourier transform infrared spectroscopy (FT-IR) analysis of LLDPE mixed with Ag-zeolite at 0.5 and $1 \%$ wt asserted Agzeolite's functional group within the plastic films. The use of the FT-IR spectrum of Ag-zeolite in this study followed what was advised in Shameli et al. (2011) report, which specified the wavenumber value Ag-zeolite at 3353, 1646, 969-461, 676, and 546-461 $\mathrm{cm}^{-1}$. It is expected to be a functional group of $\mathrm{OH}$ stretching $(\mathrm{H} 2 \mathrm{O}), \mathrm{HOH}$ bending, $\mathrm{Si}-\mathrm{O}, \mathrm{Al}-\mathrm{O}$, and $\mathrm{Si}-\mathrm{O}-\mathrm{Si}$, respectively ${ }^{(13)}$. FT-IR spectrum of LLDPE was implemented according to Ismail et al.s (2010) results ${ }^{(19)}$. The FT-IR spectra of LLDE and LLDPE / Ag-zeolite at 0.5 and $1 \%$ wt was compared to the reference spectrum, as demonstrated in [Figure 2(c)]. The result showed that the spectrum of LLDPE plastic film expressed the wave number at 2915-2848, 2639, 1470, 1378-1302, and 729-717 $\mathrm{cm}^{-1}$, expected to be a function group $\mathrm{CH}$ stretching, $-\mathrm{POH}, \mathrm{CH}$ bending, $\mathrm{S}=\mathrm{O}$, and $\mathrm{CH}$ out-of-plane bending, respectively. Compared to the FT-IR spectrum of LLDPE plastic film mixed with Ag-zeolite at 0.5 and $1 \%$ wt, the additional 

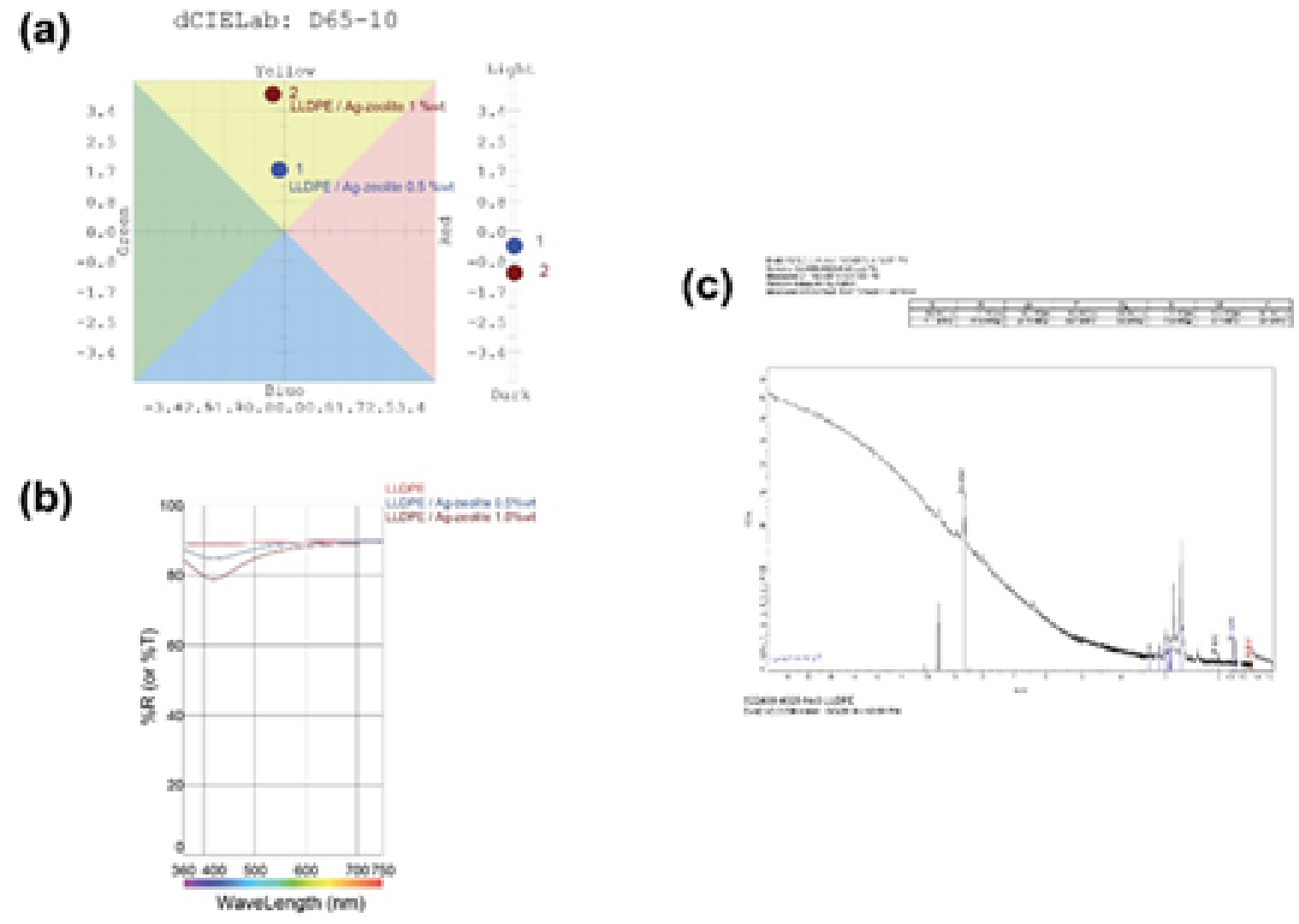

Fig 1. (a) CIE Lab*, (b) wavelength of pure LLDPE and LLDPE/Ag-zeolite at 0.5 and $1 \%$ wt films, and (c) XRF graph of LLDPE resin pellet

wave number assignment was similar to FT-IR spectral of Ag-zeolite at 3393-3183, 1654, 1541, and 1100-800 $\mathrm{cm}^{-1}$, expected to be a function group $\mathrm{OH}, \mathrm{HOH}$, and $\mathrm{Si}-\mathrm{O}$, respectively, which were the elements of Ag-zeolite.

X-ray diffraction (XRD) of LLDPE /Ag-zeolite plastic film was to examine the internal structure of the LLDPE film with Ag-zeolite added at 0.5 and 1\% wt. The Ag-zeolite agent's analysis followed what was proposed in Shameli et al.s (2011) results. The XRD spectrum result of zeolite was at 5-80 degrees ( 2 Theta). These spectra showed 35 peaks at $7.33^{\circ}, 10.38^{\circ}, 12.65^{\circ}, 16.37^{\circ}$, $21.99^{\circ}, 24.34^{\circ}, 27.51^{\circ}, 30.35^{\circ}, 31.27^{\circ}, 33.02^{\circ}, 33.85^{\circ}, 34.66^{\circ}, 36.25^{\circ}, 37.02^{\circ}, 37.78^{\circ}, 42.04^{\circ}, 42.74^{\circ}, 43.39^{\circ}, 47.9^{\circ}, 53.3^{\circ}, 55.03^{\circ}$, $57.24^{\circ}, 58.28^{\circ}, 58.37^{\circ}, 61.56^{\circ}, 63.54^{\circ}, 65.02^{\circ}, 66.06^{\circ}, 67.59^{\circ}, 69.61^{\circ}, 70.06^{\circ}, 72.23^{\circ}, 73.96^{\circ}, 78.67^{\circ}$, and $79.11^{\circ} 79.11\left(\mathrm{PXRD}^{\circ}\right.$ zeolite Ref. 01- 072-2344) and the XRD spectra of Ag show at $38.45^{\circ}, 44.77^{\circ}, 64.1^{\circ}$, and $77.12^{\circ}$ (miller indices (h k l); 111,200 , 220 , and 311 respectively (silver standard diffraction pattern of Ref. 01-087-0717) ${ }^{(13)}$ shown in [Figure 2(d)]. It can be seen that the XRD result of LLDPE indicated the peaks at $21.45^{\circ}(110), 23.43^{\circ}(200), 30.21^{\circ}(210)$, and $36.13^{\circ}$ (020) (JCPDS 00-040$1995)^{(12)}$, and when the plastic film was mixed with Ag-zeolite at 0.5 and $1 \%$ wt compared with the XRD spectra, references specified the zeolite position as $25-30^{\circ}$ in LLDPE/Ag-zeolite at 0.5 and $1 \%$ wt. The results showed that the Ag-zeolite existed within the LLDPE structure.

Meanwhile, the gloss value of the pure LLDPE film was 84; yet, when adding Ag-zeolite at 0.5 and $1 \%$ wt, the value dropped statistically significantly to 68 - 69, which was aligned with the SEM images in the surface areas and the cross-section of the LLDPE and LLDPE/Ag-zeolite films at 0.5 and $1 \%$ wt as shown in [Figure 3]. Thus, it should be noted that there were differences in Ag-zeolite distribution in LLDPE/Ag-zeolite films in both surface areas [Figure 3(b), (c)] and the cross-section area [Figure 3(e), (f)] compared with the surface area [Figure 3(a)] and cross-section area [Figure 3(d)] of the pure LLDPE films. Thereby, the increasing Ag-zeolite quantity was associated with the increasing distribution inside the surface and structure of films affecting the films' gloss, which reduced due to the reduction of the surface reflection ${ }^{(2)}$. 
(a)

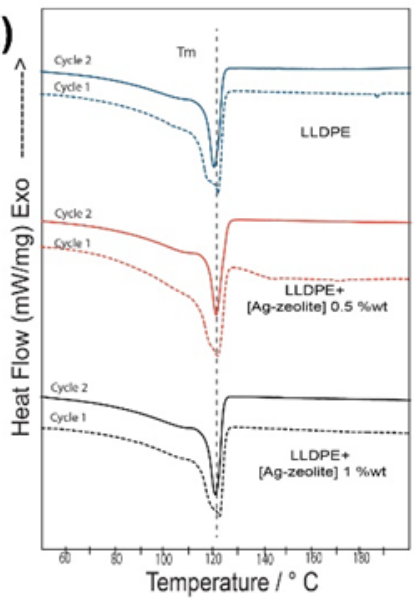

(c)

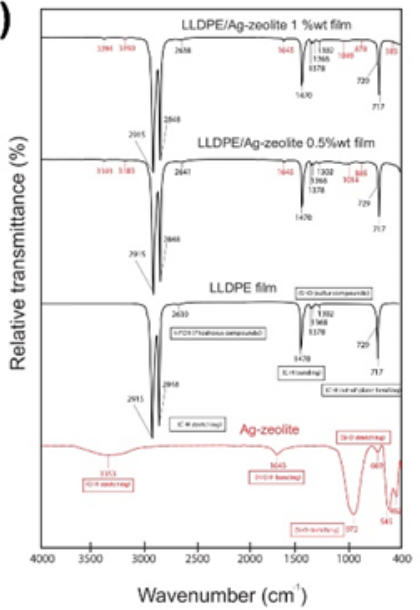

(b)

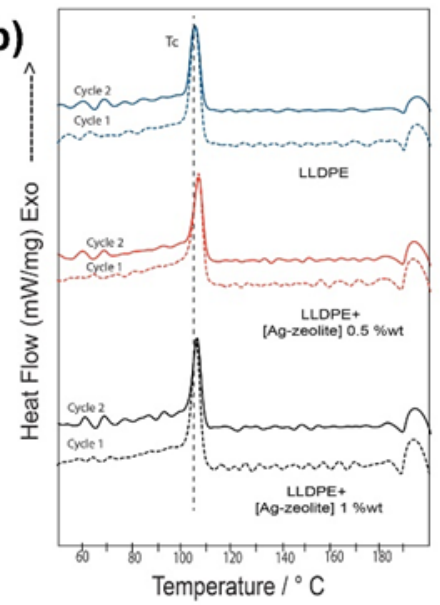

(d)

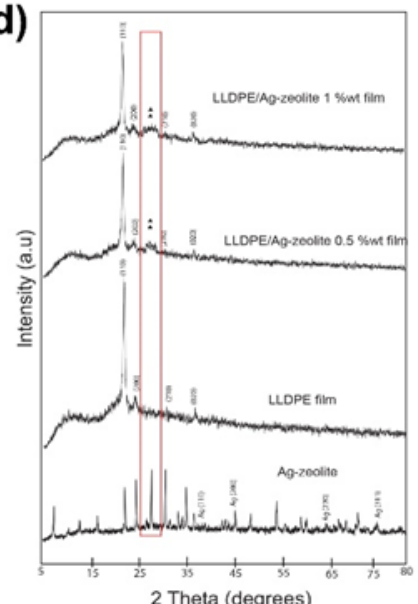

Fig 2. DSC thermograms of pure LLDPE and LDPE/Ag-zeolite at 0.5 and $1 \% \mathrm{wt}$; (a) heating and(b) cooling cycles, (c) FT-IR and (d)XRD grams of Ag-zeolite agent, pure LLDPE, and LLDPE/Ag-zeolite at 0.5 and $1 \% \mathrm{wt}$

\subsection{Mechanical properties}

The results showed that the mechanical properties of LLDPE/Ag-zeolite at 0.5 and $1 \%$ wt yielded a statistically significant decrease when Ag-zeolite was added to the plastic film, as demonstrated in [Table 1].

The average tensile strength of the LLDE film in the Mechanical direction (MD) was $25.9 \mathrm{MPa}$. When Ag-zeolite was added to the LLDPE film at 0.5 and $1 \% \mathrm{wt}$, the tensile strength significantly decreased $(p<0.05)$, reaching specifically 20.7 and 18.0 MPa, respectively. Similarly, the tensile strength of the LLDE film in the transverse direction (TD) was 22.0 MPa. When Ag-zeolite was added to the LLDPE film at 0.5 and $1 \% \mathrm{wt}$, the tensile strength significantly decreased $(p<0.05)$, reaching specifically 19.6 and $16.8 \mathrm{MPa}$, respectively. The results regarding elongation at break of the LLDE film in the MD was $259 \%$. When Ag-zeolite was added to LLDPE film at 0.5 , and $1 \%$ wt, the elongation at break significantly decreased $(p<0.05)$ to 249 and $220 \%$, respectively. Likewise, the elongation at break of LLDPE film in TD was $284 \%$. When Ag-zeolite was added to LLDPE film at 0.5 , and $1 \% \mathrm{wt}$, the elongation at break significantly decreased $(p<0.05)$ to 265 and $180 \%$, respectively. The addition of 0.5 and $1 \%$ wt of Ag-zeolite to LLDPE film resulted in the decreased tensile strength and the stretch of the LLDPE film in both $\mathrm{MD}$ and TD directions.

Tear resistance of LLDE in the MD was $4803 \mathrm{mN}$. When Ag-zeolite was added to the LLDPE film at $0.5 \mathrm{and} 1 \%$ wt, the tear resistance significantly decreased $(p<0.05)$ to 3577 and $3551 \mathrm{mN}$, respectively. Similarly, the tear resistance of LLDPE film in TD was $5263 \mathrm{mN}$. When Ag-zeolite was added to the LLDPE film at 0.5 and $1 \% \mathrm{wt}$, the tear resistance significantly decreased $(p<0.05)$ to 4842 and $4563 \mathrm{mN}$, respectively. Regarding the heat seal strength of the LLDPE film, the results indicated that 


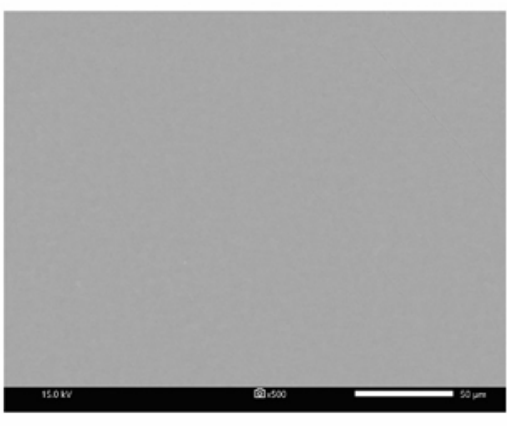

(a)

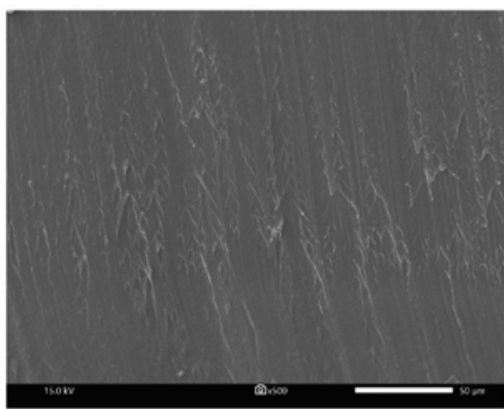

(d)

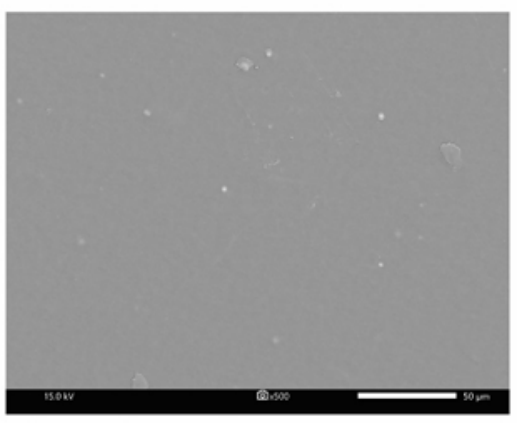

(b)

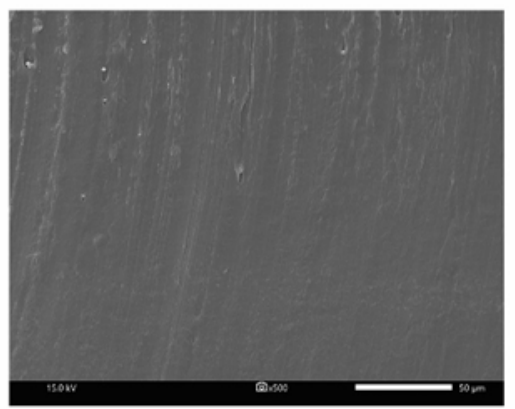

(e)

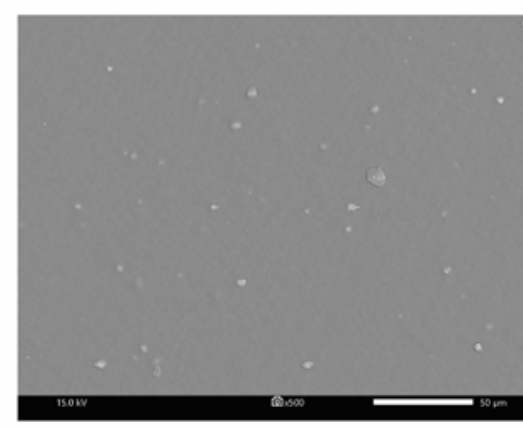

(c)

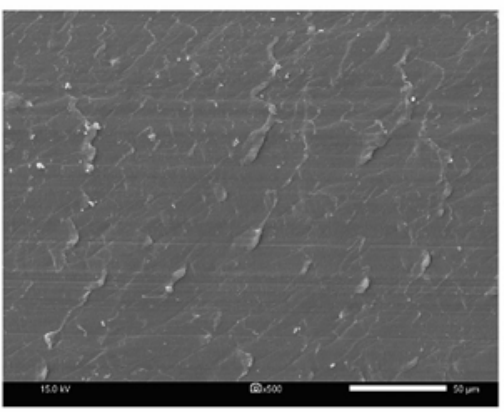

(f)

Fig 3. SEM images of surface; (a) pure LLDPE (b) LLDPE/Ag-zeolite films at $0.5 \%$ wt. (c) LLDPE/Ag-zeolite films $1 \%$ wt, and images of cross section; (d) pure LLDPE (e) LLDPE/Ag-zeolite films at $0.5 \%$ wt (f) LLDPE/Ag-zeolite films at $1 \%$ wt. [magnification at $500 \mathrm{x}, 15.0 \mathrm{kv}, 50 \mu \mathrm{m}$ ].

Table 1. Mechanical and Barrier Properties of pure LLDPE and LLDPE/Ag-zeolite at 0.5 and $1 \%$ wt

\begin{tabular}{|c|c|c|c|c|c|}
\hline Properties & & LLDPE & LLDPE /Ag-zeolite $0.5 \%$ wt & LLDPE /Ag-zeolite $1 \% w t$ & P-value \\
\hline \multirow{2}{*}{ Tensile strength $(\mathrm{MPa})$} & MD & $25.9 \pm 1.50^{\mathrm{A}}$ & $20.7 \pm 1.54^{\mathrm{B}}$ & $18.0 \pm 1.26^{\mathrm{B}}$ & $0.00^{*}$ \\
\hline & TD & $22.0 \pm 2.69^{\mathrm{A}}$ & $19.6 \pm 1.78^{\mathrm{A}}$ & $16.8 \pm 1.53^{\mathrm{B}}$ & $0.00^{\star}$ \\
\hline \multirow{2}{*}{ Elongation at break (\%) } & MD & $259 \pm 10.9^{\mathrm{A}}$ & $249 \pm 6.96^{\mathrm{B}}$ & $220 \pm 10.9^{\mathrm{C}}$ & $0.01^{*}$ \\
\hline & TD & $284 \pm 14.7^{\mathrm{A}}$ & $265 \pm 7.98^{\text {B }}$ & $180 \pm 8.67^{\text {B }}$ & $0.03^{\star}$ \\
\hline \multirow{2}{*}{ Tear strength $(\mathrm{mN})$} & $\mathrm{MD}$ & $4803 \pm 390^{\mathrm{A}}$ & $3577 \pm 329^{\mathrm{B}}$ & $3551 \pm 311^{\mathrm{B}}$ & $0.02^{*}$ \\
\hline & $\mathrm{TD}$ & $5263 \pm 302^{\mathrm{A}}$ & $4842 \pm 378^{\mathrm{B}}$ & $4563 \pm 281^{\mathrm{B}}$ & $0.00^{*}$ \\
\hline Heat seal strength $(\mathrm{mN})$ & & $13800 \pm 103^{A}$ & $10963 \pm 102^{B}$ & $10400 \pm 105^{B}$ & $0.01^{*}$ \\
\hline Puncture resistance $(\mathrm{J})$ & & $0.07 \pm 0.00^{\mathrm{A}}$ & $0.04 \pm 0.00^{\mathrm{B}}$ & $0.04 \pm 0.00^{\mathrm{B}}$ & $0.00^{*}$ \\
\hline OTR (cc/m2/day) & & $3049 \pm 48.8^{\mathrm{A}}$ & $3434.5 \pm 178.9^{\mathrm{A}}$ & $3445 \pm 127.3^{\mathrm{A}}$ & 0.09 \\
\hline WVTR (g/m2/day) & & $6.72 \pm 0.12^{\mathrm{A}}$ & $6.77 \pm 0.37^{\mathrm{A}}$ & $6.78 \pm 0.43^{\mathrm{A}}$ & 0.08 \\
\hline
\end{tabular}

${ }^{*}$ The mean difference is significant at the 0.05 level $(\mathrm{P}$-value $<0.05)$. 
the force to pull the film bond of the LLDPE film was $13800 \pm 103 \mathrm{mN}$. When added to the LLDPE film at 0.5 and $1 \%$ wt, the heat seal strength significantly decreased $(p<0.05)$ with the value of $10963 \pm 102$ and $10400 \pm 105 \mathrm{mN}$, respectively. Puncture resistance of LLDPE film results showed that the punching force of LLDPE film was $0.07 \pm 0.01 \mathrm{~J}$. When added to LLDPE film at 0.5 and $1 \% \mathrm{wt}$, the puncture resistance significantly decreased $(p<0.05)$ to $0.04 \pm 0.00 \mathrm{~J}$.

In the study of Kim et al.s (2008), the reasons for the decrease in the polymer's mechanical properties when zeolites (rigid inorganic) in the polymer were added, causing a new interface and stress concentration, were explained. Both were the weaknesses that accounted for the reduction in the mechanical properties of plastics ${ }^{(20)}$. The primary problem with the poor interface is the connection of two incompatible substances, including zeolite (hydrophilic) and LLDPE polymers (hydrophobic), which contributed to the poor compatibility and dispersibility within the LLDPE matrix ${ }^{(21,22)}$. Leong et al. (2004) described that by adding more zeolite to the polymer, the tensile strength decreased since zeolite particles replaced the mainchain of LLDPE, and zeolite binding might then occur, causing nonbonding between Zeolite particles and polymer and non-homogeneous ${ }^{(23)}$. These reasons were consistent with the SEM image shown in [Figure 3 ] since the distribution of zeolite in the surface area and the insertion inside the structure (cross-section) created weak planes of the molecule arrangement ${ }^{(2)}$. The distribution of zeolite in the cross-section was another reason. That is, it caused a decrease in tensile strength. Demir et al. (2006) reported about zeolite particles, which caused voids within polymer and reduction in the effective matrix cross-section of polymer matrix ${ }^{(23)}$. Basalp et al. (2008) reported polyethylene film results when mixed Zeolite-Y, discovering that tensile strength, elongation at break, tear-resistance, and puncture resistance decreased ${ }^{(24)}$.

Notwithstanding, Mihindukulasuriya et al. (2014) reviewed the existing literature related to food packaging development, addressing several studies involving the mechanical properties results from experimenting with the nanocomposite. Overall, when the additive agent (nanoparticle) was included in some polymers, it enhanced those polymers' maniacal properties ${ }^{(25)}$. In addition, Zampino et al. (2011) examined polyvinyl chloride (PVC) mixed with Ag-zeolite at 2-20\% wt, discovered that the increased amount of the agent in PVC film affected the improvement of the maniacal properties (tensile strength and elongation at break) of those polymer ${ }^{(26)}$. In this particular research, the decrease of the mechanical properties of the LLDPE mixed with Ag-zeolite at 0.5 and $1 \%$ wt film possibly from the manufacturing processes. Vasile's (2018) study described how nanocomposite was produced by the extrusion method. The study revealed that the method had difficulty controlling the heat transfer in the unit operations and the homogeneity between polymer resin and nanoparticle additive, which could probably affect the mechanical properties of the film. Additionally, Vasile (2018) suggested that, in the process of manufacturing, a coating technique should be used to replace extrusion, especially in case the tensile strength changes when added the substances. This is due to the coating technology being compatible with Nano surface biocides production. This is actually in line with this existing study's scope because the agent used consisted of silver nanoparticles, which provided an antibacterial property. There are several coating technologies used with the Nano surface biocides, including non-covalent (migratory), covalent (nonmigratory), photographing chemistries, layer-by-layer deposition, and embedding for controlled release ${ }^{(27)}$.

\subsection{Barrier properties}

The experiments' results revealed the barrier properties of the LLDPE and LLDPE/Ag-zeolite plastic film, demonstrated in [Table 1]. Overall, it was discovered that the oxygen transmission rates (OTR) of pure LLDPE and LLDPE/Ag-zeolite at 0.5 and $1 \% \mathrm{wt}$ were insignificant changed $(p<0.05)$. The water vapor transmission rates (WVTR) of pure LLDPE and LLDPE/Agzeolite at 0.5 and $1 \%$ wt were also insignificant changes $(p<0.05)$.

From the results, it was distinct that when adding 0.5 and $1 \%$ wt of Ag-zeolite agent to the LLDPE plastic film, it did not affect the plastic films' OTR and WVTR. Taking account of the structure of LLDPE, it was found that LLDPE was developed from LDPE; that is, LLDPE had a shorter branch than LDPE. As a result, the internal structure was more organized than LDPE, contributing to better barrier properties ${ }^{(4)}$. Kim et al. (2018) touched upon the physical properties (DSC) of composite mixed with zeolite agent related to OTR and WVTR of the composite ${ }^{(28)}$, which was consistent with DSC in this research, as shown in [Figure 2 (a), (b)]. Thus, it is possible that this might not also affect the OTR and WVTR rates of plastic films. However, Mihindukulasuriya et al. (2014), addressing the inclusion of nanoparticles in other polymers, found that WVTR and OTR of those films decreased, which means the nanoparticle additives would enhance the barrier properties of the films ${ }^{(25)}$.

\section{Conclusions}

The results from the series of the experiments indicated that when Ag-zeolite agent (0.5 and 1\% wt) was added in LLFPE films, those films did not change the characteristics and the structures of polymer; it conformed to the other case study, while it changed from the transparent color to yellow. Meanwhile, the mechanical properties of LLDPE mixed with Ag-zeolite agent tended to decrease when the amount of Ag-zeolite agent in the film increased. When Ag-zeolite agent was added in the films, it 
did not affect the barrier properties of those films; it contrasted with the other case study that adding nanoparticle in polymer should enhance mechanical barrier properties of those film, which possibly from the different process manufacturing.

\section{Acknowledgement}

The authors acknowledge the Petch Pra Jom Klao Master's Degree Research Scholarship from the King Mongkut's University of Technology Thonburi for researching that has contributed to the research results reported within this paper.

\section{References}

1) Birley AW. Plastics materials: properties and applications. and others, editor;Springer Science and Business Media. 2012.

2) Selke S, Culter J. Plastics packaging: properties, processing, applications, and regulations. 2016.

3) Dennis C, Stringer M. Chilled foods: a comprehensive guide. Ellis Horwood. 1992.

4) Abdel-Bary EM. Handbook of plastic films. 2003.

5) Tornuk F, Hancer M, Sagdic O, Yetim H. LLDPE based food packaging incorporated with nanoclays grafted with bioactive compounds to extend shelf life of some meat products. LWT - Food Science and Technology. 2015;64(2):540-546. Available from: https://dx.doi.org/10.1016/j.lwt.2015.06.030.DOI: 10.1016/j.lwt.2015.06.030.

6) Panrong T, Karbowiak T, Harnkarnsujarit N. Thermoplastic starch and green tea blends with LLDPE films for active packaging of meat and oil-based products. Food Packaging and Shelf Life. 2019;21:100331. Available from: https://dx.doi.org/10.1016/j.fpsl.2019.100331.

7) Ebnesajjad S. Plastic films in food packaging: materials, technology, and applications. 2012.

8) Brody A, Strupinsky E, Kline L. Active packaging for food applications. CRC press. 2001.

9) Dutta P, Wang B. Zeolite-supported silver as antimicrobial agents. Coordination Chemistry Reviews. 2019;383:1-29. Available from: https://dx.doi.org/ 10.1016/j.ccr.2018.12.014.

10) Le A, Dang V, Nguyen N, Vu C, Nguyen Q. Preparation of polypropylene/silver nano-zeolite plastics and evaluation of antibacterial and mechanical properties. International Journal of Composite Materials. 2016;6(4):89-94. doi:10.5923/j.cmaterials.20160604.01.

11) Carbone M, Donia DT, Sabbatella G, Antiochia R. Silver nanoparticles in polymeric matrices for fresh food packaging. Journal of King Saud University Science. 2016;28(4):273-279. Available from: https://dx.doi.org/10.1016/j.jksus.2016.05.004.

12) Alaburdaite R, Paluckiene E, Grevys S. Comparison of the surface characteristics of polyethylene and polypropylene films and polyester textile coated with electroconductive copper sulphide thin films. Chalcogenide Letters. 2016;13(12):529-536. Available from: https://chalcogen.ro/529_AlaburdaiteR.pdf.

13) Shameli K, Ahmad M, Mohsen Z, Yunis WZ, Ibrahim NA. Fabrication of silver nanoparticles doped in the zeolite framework and antibacterial activity. International Journal of Nanomedicine. 2011;6(331). Available from: https://dx.doi.org/10.2147/ijn.s16964.

14) Kuehni RG. Color: An introduction to practice and principles. John Wiley \& Sons. 2012.

15) Pridmore RW. Complementary colors: The structure of wavelength discrimination, uniform hue, spectral sensitivity, saturation, chromatic adaptation, and chromatic induction. Color. 2009;34(3):233-252. Available from: https://dx.doi.org/10.1002/col.20490.

16) Boschetto DL, Lerin L, Cansian R, Pergher S, Luccio MD. Preparation and antimicrobial activity of polyethylene composite films with silver exchanged zeolite-Y. Chemical Engineering Journal. 2012;204:210-216. Available from: https://dx.doi.org/10.1016/j.cej.2012.07.111.

17) Morones JR, Elechiguerra JL, Camacho A, Holt K, Kouri JB, Ramírez JT. The bactericidal effect of silver nanoparticles. Nanotechnology. 2005;16(10):23462353. Available from: https://dx.doi.org/10.1088/0957-4484/16/10/059.

18) Passador FR, Filho A, Pessan LA. Structural characterization of HDPE/LLDPE and OMMT blend-based nanocomposites obtained by different blending sequences. Polímeros. 2012;22(4):357-363. Available from: http://dx.doi.org/10.1590/S0104-14282012005000052.

19) Ismail H, Nordin R, Ahmad Z, Rashid A. Processability and miscibility of linear low-density polyethylene/poly (vinyl alcohol) blends Insitu compatibilization with maleic acid. Iranian Polymer Journal. 2010;4(118):297-308. Available from: https://www.sid.ir/en/journal/ViewPaper.aspx?id= 169658.

20) Kim HS, Kim HJ. Influence of the zeolite type on the mechanical-thermal properties and volatile organic compound emissions of natural-flour-filled polypropylene hybrid composites. Journal of applied polymer science. 2008;110(5):3247-3255. Available from: https://doi.org/10.1002/app.28853.

21) Kundu PP, Biswas J, Kim H, Shim SE, Choe S, Lee DS. Effect of calcite and calcite/zeolite hybrid fillers on LLDPE and PP composites. Advances in Polymer Technology. 2004;23(3):230-238. Available from: https://dx.doi.org/10.1002/adv.20013.

22) Ray SS, Okamoto M. Polymer/layered silicate nanocomposites: a review from preparation to processing. Progress in Polymer Science. 2003;28:1539-1641. Available from: https://dx.doi.org/10.1016/j.progpolymsci.2003.08.002.

23) Leong YW, Bakar M, Ishak Z, Ariffin A, Pukanszky B. Comparison of the mechanical properties and interfacial interactions between talc, kaolin, and calcium carbonate filled polypropylene composites. Journal of Applied Polymer Science. 2004;91(5):3315-3326. Available from: https://dx.doi.org/10.1002/ app.13542.

24) Basalp D, Tihminlioğlu F. The effects of natural zeolite and silane coupling agents on melting and crystallization behaviour of polypropylene. Journal of Thermal Analysis and Calorimetry. 2008;94(3):757-765. Available from: https://dx.doi.org/10.1007/s10973-008-9367-6.

25) Mihindukulasuriya SDF, Lim LT. Nanotechnology development in food packaging: A review. Trends in Food Science \& Technology. 2014;40(2). Available from: https://doi.org/10.1016/j.tifs.2014.09.009.

26) Zampino D, Ferreri T, Puglisi C, Mancuso M, Zaccone R, Scaffaro R. PVC silver zeolite composites with antimicrobial properties. Journal of Materials Science. 2011;46(20):6734-6743. Available from: https://dx.doi.org/10.1007/s10853-011-5629-y.

27) Vasile C. Polymeric nanocomposites and nanocoatings for food packaging: A review. Materials. 2018;11(10):1834. Available from: https://doi.org/10. 3390/ma11101834.

28) Kim D, Thanakkasaranee S, Seo J, Khan SB. Effect of porous zeolite on temperature-dependent physical properties of polypropylene/octadecane (PP/OD) composite films. Express Polymer Letters. 2018;12(7):658-674. Available from: https://dx.doi.org/10.3144/expresspolymlett.2018.56. 